\title{
Long-Term Safety of Adalimumab in 29,967 Adult Patients From Global Clinical Trials Across Multiple Indications: An Updated Analysis
}

\author{
Gerd R. Burmester (D) - Kenneth B. Gordon • James T. Rosenbaum • \\ Dilek Arikan · Winnie L. Lau • Peigang Li · Freddy Faccin • \\ Remo Panaccione
}

Received: October 8, 2019 / Published online: November 20, 2019

(C) The Author(s) 2019

\section{ABSTRACT}

Introduction: The safety profile of adalimumab was previously reported in 23,458 patients across multiple indications. Here we report the long-term safety of adalimumab in adults with plaque psoriasis (Ps), hidradenitis suppurativa (HS), rheumatoid arthritis (RA), ankylosing spondylitis, psoriatic arthritis, non-radiographic axial spondyloarthritis, peripheral spondyloarthritis, Crohn's disease (CD), ulcerative colitis (UC), and non-infectious uveitis (UV).

Enhanced Digital Features To view enhanced digital features for this article go to https://doi.org/10.6084/ m9.figshare.10070138.

\section{G. R. Burmester $(\square)$}

Charité Universitätsmedizin Berlin, Berlin, Germany

e-mail: gerd.burmester@charite.de

K. B. Gordon

Medical College of Wisconsin, Milwaukee, WI, USA

J. T. Rosenbaum

Oregon Health and Science University and Legacy

Devers Eye Institute, Portland, OR, USA

D. Arikan · W. L. Lau · P. Li · F. Faccin

AbbVie, North Chicago, IL, USA

R. Panaccione

University of Calgary, Calgary, AB, Canada
Methods: Safety data from 77 clinical trials were pooled. Safety assessments included adverse events (AEs) and serious AEs (SAEs) that occurred after the first study dose and within 70 days ( 5 half-lives) after the last study dose.

Results: A total of 29,967 patients were included, representing 56,916 patient-years (PY) of exposure. The most frequently reported SAE of interest was infection (3.7/100 PY) with highest incidences in CD, RA, UV, and UC (3.5/ 100 PY-6.9/100 PY); serious infections in Ps $(1.8 / 100 \mathrm{PY})$ and HS (2.8/100 PY) were lower. The observed number of deaths was below what would be expected in an age- and sex-adjusted population for most adalimumab-treated patients (including Ps). Lack of real-life data and limited long-term data ( $>5$ years) for most patients are limitations of this analysis.

Conclusion: The safety profile of adalimumab was consistent with previous findings and no new safety signals were observed.

Keywords: Adalimumab; Ankylosing spondylitis; Crohn's disease; Hidradenitis suppurativa; Long-term safety; Plaque psoriasis; Psoriatic arthritis; Rheumatoid arthritis; Ulcerative colitis; Uveitis 


\section{Key Summary Points}

Why carry out this study?

The long-term safety of adalimumab was previously reported in 23,458 patients representing up to 12 years of clinical trial exposure.

Since the previous analysis, adalimumab has been approved for new indications (e.g., hidradenitis suppurativa and noninfectious uveitis) and additional clinical trial data across indications became available.

The objective of this updated analysis was to examine the safety of adalimumab in adult patients with plaque psoriasis, hidradenitis suppurativa, rheumatoid arthritis, ankylosing spondylitis, psoriatic arthritis, non-radiographic axial spondyloarthritis, peripheral spondyloarthritis, Crohn's disease, ulcerative colitis, and non-infectious uveitis, with a special focus on mortality rates with extended adalimumab treatment.

\section{What was learned from the study?}

This analysis of adalimumab trials with 56,916 patient-years of exposure demonstrated an overall safety profile consistent with previous findings and with other anti-tumor necrosis factor agents.

No new safety signals or tolerability issues were identified, and the risk of mortality was not increased compared with the general population.

\section{INTRODUCTION}

Adalimumab (HUMIRA ${ }^{\circledR}$, AbbVie, North Chicago, IL) is an anti-tumor necrosis factor (TNF) agent indicated for the treatment of
15 conditions, including adult and pediatric plaque psoriasis (Ps), hidradenitis suppurativa (HS), rheumatoid arthritis (RA), psoriatic arthritis (PsA), ankylosing spondylitis (AS), nonradiographic axial spondyloarthritis (nr-axSpA), polyarticular juvenile idiopathic arthritis (pJIA), enthesitis-related arthritis, adult and pediatric Crohn's disease (CD), ulcerative colitis (UC), adult and pediatric uveitis (UV), and Behçet's disease $[1,2]$.

The long-term safety of adalimumab was previously reported in 23,458 patients representing up to 12 years of clinical trial exposure [3]. Infections were the most frequently reported serious events, ranging from 1.4/100 patientyears (PY) to 6.7/100 PY across indications [3]. Non-melanoma skin cancer (NMSC) incidence rates were higher in Ps, RA, and CD compared with 10-year age-specific incidence rates in the USA from 1977 to 1978, but the overall malignancy rates (excluding NMSC) were as expected for the general population. Death rates were lower or equivalent to rates expected for the general population. The safety profile of adalimumab was also consistent with that of anti-TNF agents in real-world registries [4-7].

Since the previous analysis, adalimumab has been approved for new indications (e.g., HS and UV) and additional clinical trial data across indications have become available $[1,2]$. The objective of this updated analysis was to examine the safety of adalimumab in adult patients with Ps, HS, RA, AS, nr-axSpA, peripheral SpA (pSpA), PsA, CD, UC, and UV, with a special focus on mortality rates with extended adalimumab treatment.

\section{METHODS}

\section{Clinical Trials}

Safety data from 77 clinical trials of adalimumab (33 RA [8-30], 13 Ps [31-44], 11 CD [45-57], 5 AS [58-62], 4 UC [63-67], 3 HS [68, 69], 3 PsA [70-73], 2 UV [74-76], 2 nr-axSpA $[77,78], 1 \mathrm{pSpA}$ [79]) were included from randomized controlled, open-label, and longterm extension studies conducted through 
December 31, 2016. Adalimumab postmarketing surveillance data were not included in this analysis because of limitations associated with voluntary reporting. Of note, this analysis did not include pediatric patients; a separate analysis on pediatric safety was recently published [80].

The studies were conducted in accordance with the International Conference on Harmonisation Good Clinical Practice guidelines and the Declaration of Helsinki, and were approved by institutional review boards and/or independent ethics committees according to local law. All patients provided informed consent before any study procedures were conducted.

\section{Safety Assessments}

Safety assessments included all treatment-emergent adverse events (AEs) and serious AEs (SAEs) that occurred after the first adalimumab study dose and within 70 days ( 5 half-lives) after the last study dose. Events that were fatal or life threatening, required in-patient or prolonged hospitalization, resulted in persistent or significant disability/incapacity or congenital anomaly, required medical or surgical intervention to prevent a serious outcome, or other medically important conditions (e.g., miscarriage/spontaneous abortion, elective abortion) were categorized as SAEs. AEs were coded using the Medical Dictionary for Regulatory Activities version 19.1 preferred terms (https://www.meddra.org/). SAEs of interest included infections (including opportunistic infections and tuberculosis [TB]), demyelinating disorder, lupus-like syndrome, congestive heart failure (CHF), new onset or worsening of psoriasis, malignancy (including lymphoma, non-melanoma skin cancer [NMSC], and melanoma), and sarcoidosis. Rates are reported as events per 100 PY. Kaplan-Meier analyses were used to evaluate the time to first serious infection event and the time to first malignancy (excluding lymphoma, hepatosplenic T-cell lymphoma, leukemia, NMSC, and melanoma).

Standardized incidence rates (SIRs) were calculated as the ratio of observed to expected number of malignancies; 95\% CIs for SIRs were calculated assuming that observed malignancies followed a Poisson distribution. To correspond with previously conducted SIR analyses of longterm adalimumab safety data, the data from the ReAlise uncontrolled observational study of patients with RA [23] were not included. The expected numbers of malignancies, excluding NMSC, for SIR calculations were based on 5-year, age-specific incidence rates from the National Cancer Institute (NCI) Surveillance, Epidemiology, and End Results (SEER) database, 2000-2007 (http://www.seer.cancer.gov). No similar database is available for Europe, Australia, or Canada, so an assumption was made that patients from these regions could be pooled with those from the USA. Because the NCI SEER database does not include NMSC, NMSC rates were based on age-specific incidence rates from an NCI survey in the USA from 1977 to 1978 [81].

Standardized mortality rates (SMR) were calculated as the ratio of observed deaths to expected deaths estimated on the basis of country-specific, baseline age- and sex-matched population data from the World Health Organization for 1997-2006 (https://www.who.int/ gho/publications/world_health_statistics/whostat 2006_erratareduce.pdf). The confidence interval of the SMR was calculated with a formula from Breslow and Day that uses Byar's approximation [82].

\section{RESULTS}

This analysis included 29,967 patients representing 56,916 PY of exposure. Baseline characteristics are summarized in Table 1. The highest adalimumab exposure was in the RA studies $(37,106 \mathrm{PY})$, followed by Ps (5479 PY). Overall, 9355 patients had more than 2 years of exposure and 4003 patients had more than 5 years of exposure.

A total of 3867 (12.9\%) patients discontinued because of a treatment-emergent $\mathrm{AE}$ (8.7/ $100 \mathrm{PY})$. The most common AEs leading to discontinuation in the total population were Crohn's disease $(0.4 / 100 \mathrm{PY})$, rheumatoid arthritis (0.3/100 PY), ulcerative colitis (0.3/ $100 \mathrm{PY})$, and pneumonia (0.2/100 PY); all other events were reported with a rate of at most 


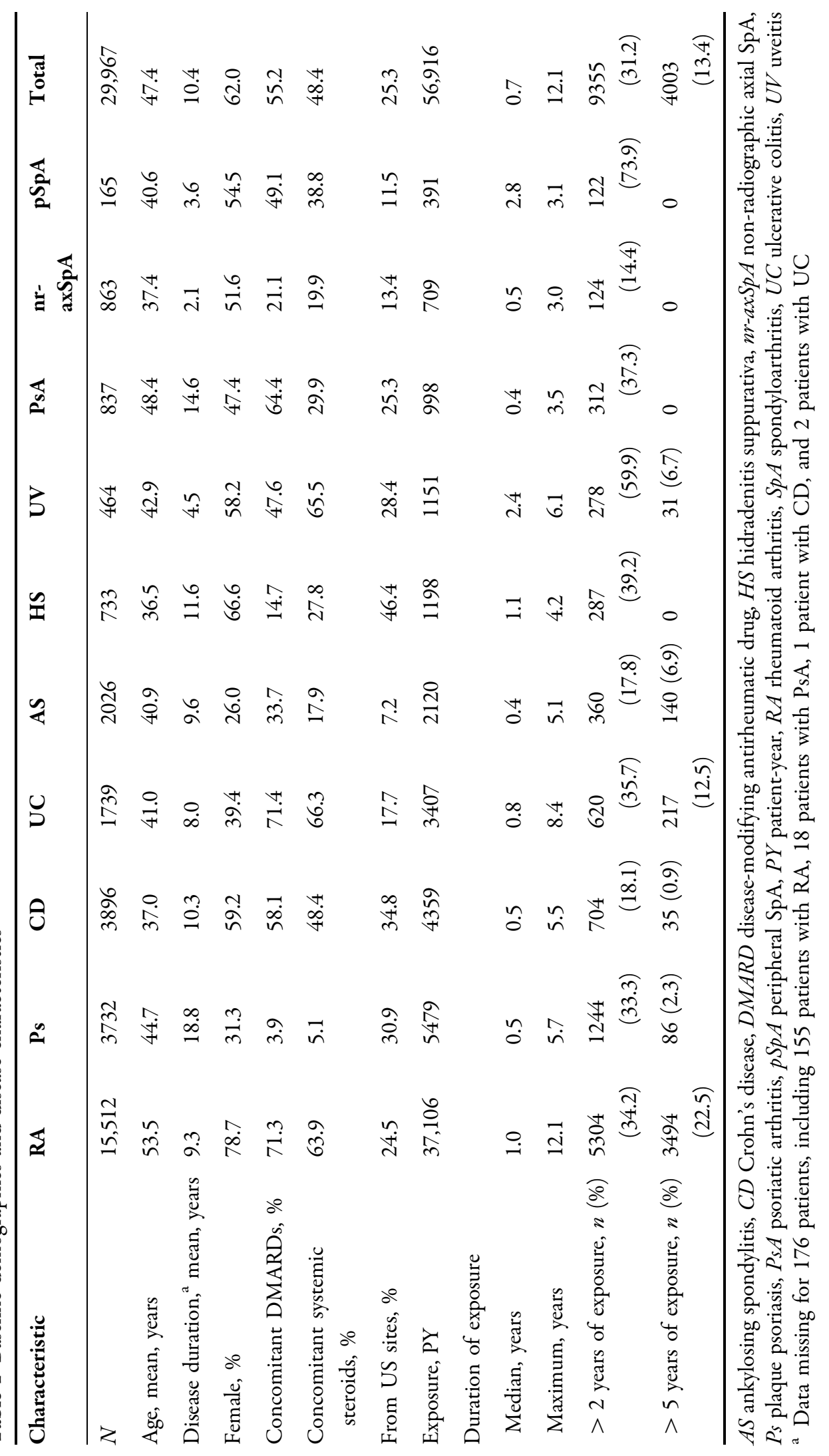


Table 2 Incidence rates of serious adverse events of interest

\begin{tabular}{llllllllllll}
\hline SAE $^{\mathbf{a}}$ & RA & Ps & CD & UC & AS & HS & UV & PsA & nr-axSpA & pSpA & Total \\
\hline$N$ & 15,512 & 3732 & 3896 & 1739 & 2026 & 733 & 464 & 837 & 863 & 165 & 29,967 \\
Exposure, PY & 37,106 & 5479 & 4359 & 3407 & 2120 & 1198 & 1151 & 998 & 709 & 391 & 56,916 \\
Infection & 3.9 & 1.8 & 6.9 & 3.5 & 1.8 & 2.8 & 4.1 & 2.8 & 2.5 & 1.0 & 3.7 \\
Tuberculosis & 0.2 & 0.2 & 0.2 & $<0.1$ & 0.1 & 0 & 0.4 & 0.2 & 0.1 & 0.3 & 0.2 \\
Active & 0.2 & 0.2 & 0.1 & $<0.1$ & 0.1 & 0 & 0.2 & 0.2 & 0.1 & 0 & 0.2 \\
Latent $_{\text {Opportunistic infection }}{ }^{\mathrm{b}}$ & $<0.1$ & 0 & $<0.1$ & 0 & 0 & 0 & 0.3 & 0 & 0 & 0.3 & $<0.1$ \\
Demyelinating disorder $^{\mathrm{c}}$ & $<0.1$ & 0 & $<0.1$ & $<0.1$ & 0 & 0 & 0.4 & 0 & 0.1 & 0 & $<0.1$ \\
Lupus-like syndrome $_{\text {CHF }}^{\mathrm{d}}$ & $<0.1$ & 0 & $<.1$ & $<0.1$ & $<0.1$ & 0 & 0.3 & 0 & 0 & 0 & $<0.1$ \\
Ps $^{\mathrm{e}}$ & 0.2 & 0.1 & 0 & $<0.1$ & $<0.1$ & 0.2 & $<0.1$ & 0 & 0 & 0 & 0.2 \\
Malignancy $^{\mathrm{f}}$ & $<0.1$ & $<0.1$ & $<0.1$ & $<0.1$ & $<0.1$ & $<0.1$ & 0 & 0.1 & 0 & 0 & $<0.1$ \\
Lymphoma & 0.7 & 0.5 & 0.4 & 0.6 & 0.2 & 0.5 & 0.7 & 0.2 & 0.1 & 0.3 & 0.6 \\
NMSC $_{\text {Melanoma }}^{0.1}$ & $<0.1$ & $<0.1$ & $<0.1$ & $<0.1$ & $<0.1$ & $<0.1$ & 0.2 & 0 & 0 & $<0.1$ \\
Sarcoidosis & 0.2 & 0.1 & $<0.1$ & $<0.1$ & 0.2 & $<0.1$ & 0.2 & 0.1 & 0 & 0 & 0.1 \\
Any AE leading to death & 0.6 & 0.2 & 0.1 & 0.1 & $<0.1$ & 0.5 & 0.6 & 0.3 & 0.3 & 1.0 & 0.5 \\
\hline
\end{tabular}

$A E$ adverse event, $A S$ ankylosing spondylitis, $C D$ Crohn's disease, $C H F$ congestive heart failure, $H S$ hidradenitis suppurativa, $N M S C$ non-melanoma skin cancer, $n r$-axSpA non-radiographic axial SpA, $P s$ plaque psoriasis, $P s A$ psoriatic arthritis, $p S p A$ peripheral SpA, $P Y$ patient-year, $R A$ rheumatoid arthritis, $S A E$ serious adverse event, $S p A$ spondyloarthritis, $U C$ ulcerative colitis, $U V$ uveitis

a Reported in events/100 PY

b Excludes oral candidiasis and tuberculosis

c Includes multiple sclerosis (8 events), demyelination (7 events), optic neuritis (6 events), Guillain-Barré syndrome (3 events), and leukoencephalopathy (1 event)

d Includes cardiac failure congestive ( 44 events), cardiac failure (34 events), right ventricular failure ( 5 events), cardiogenic shock ( 3 events), cardiac failure acute ( 3 events), pulmonary edema ( 3 events), left ventricular dysfunction ( 2 events), left ventricular failure ( 2 events), and acute left ventricular failure ( 1 event)

e New onset or worsening

f Excludes lymphoma, hepatosplenic T-cell lymphoma, leukemia, NMSC, and melanoma

0.1/100 PY. Most of these observed discontinuations can be attributed to the underlying disease or its complications.

Serious infections were the most frequent SAEs of interest across all indications (3.7/ $100 \mathrm{PY}$ ), with the highest incidences in $\mathrm{CD}, \mathrm{UV}$, RA, and UC studies (3.5-6.9/100 PY); rates in pSpA (1.0/100 PY), Ps (1.8/100 PY), and AS (1.8/
$100 \mathrm{PY}$ ) were lower (Table 2). Overall, the most commonly reported serious infections were pneumonia (0.6/100 PY) and cellulitis (0.2/ $100 \mathrm{PY})$. The most common serious infections in RA, Ps, and HS were pneumonia (0.7/100 PY, $0.3 / 100 \mathrm{PY}$, and $0.3 / 100 \mathrm{PY})$, cellulitis (0.2/ $100 \mathrm{PY}, 0.3 / 100 \mathrm{PY}$, and $0.3 / 100 \mathrm{PY})$, arthritis bacterial (0.2/100 PY, RA only), and pilonidal 
cyst (0.3/100 PY, HS only). For other indications, the most common serious infections were cellulitis (0.6/100 PY) and appendicitis (0.3/ $100 \mathrm{PY}$ ) in nr-axSpA; urinary tract infection $(0.5 / 100 \mathrm{PY})$ and pneumonia (0.4/100 PY) in $\mathrm{UV}$; urinary tract infection (0.4/100 PY), appendicitis (0.2/100 PY), and diverticulitis
(0.2/100 PY) in PsA; anal (1.0/100 PY) and abdominal (0.7/100 PY) abscess in CD; and pneumonia (0.5/100 PY) and appendicitis (0.3/ $100 \mathrm{PY}$ ) in UC. In pSpA studies, four serious infections were reported (cellulitis, diverticulitis, pyelonephritis, and hemorrhagic cystitis; 0.3/100 PY each). In AS, cellulitis (0.2/100 PY)

Time to first serious infection
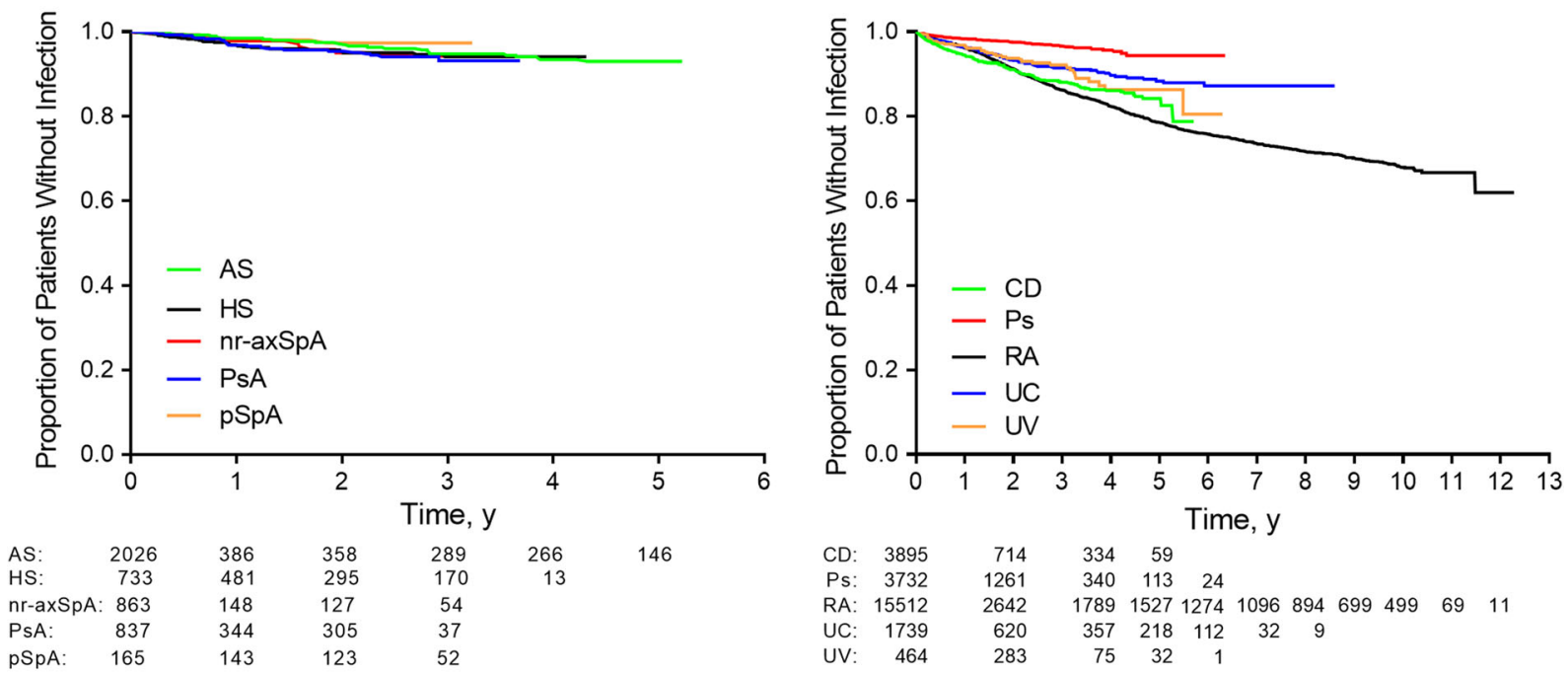

Time to first malignancy

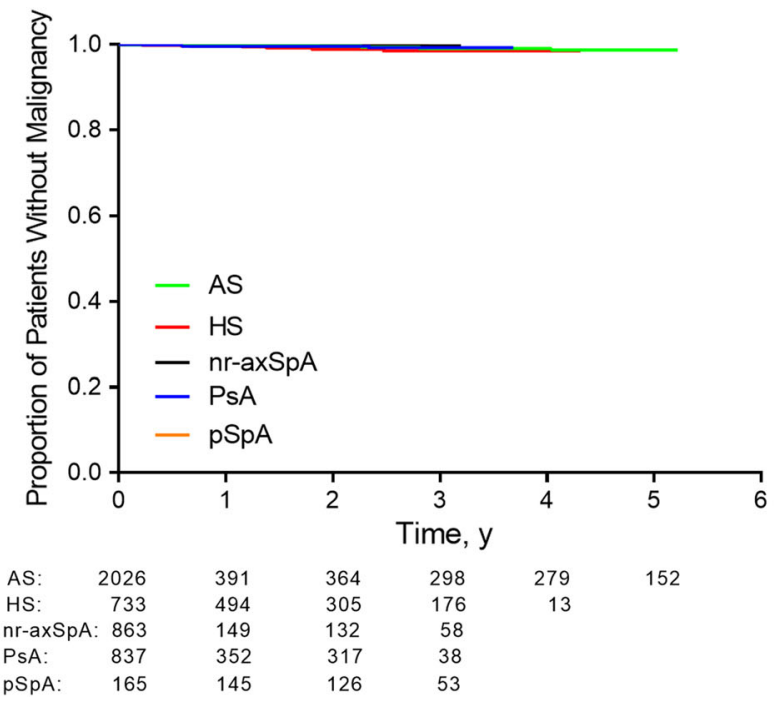

Fig. 1 Time to first serious infection by indication and time to first malignancy, other than lymphoma, hepatosplenic T-cell lymphoma, leukemia, NMSC, and melanoma by indication. Numbers of patients assessed at each time point for each indication are shown below each

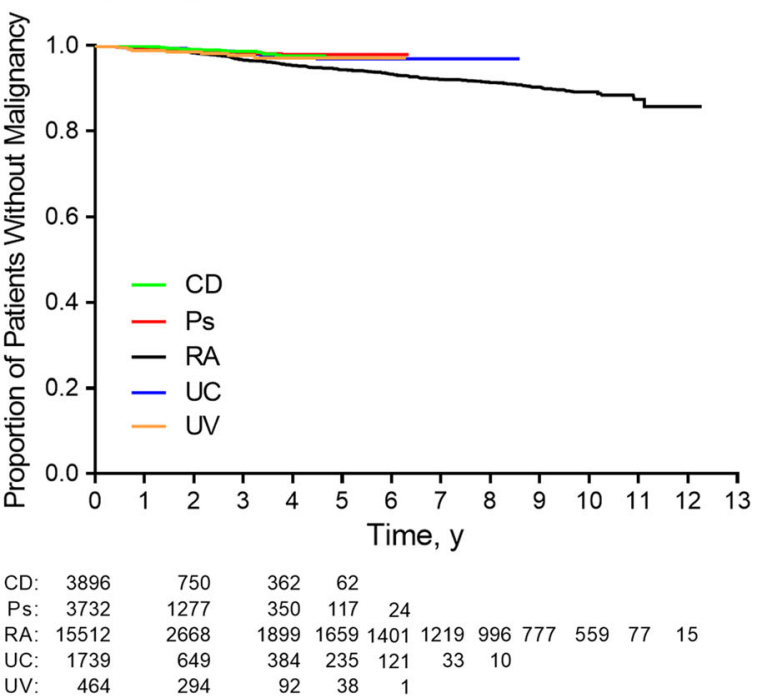

graph. $A S$ ankylosing spondylitis, $C D$ Crohn's disease, $H S$ hidradenitis suppurativa, $n r-a x S p A$ non-radiographic axial SpA, $P s$ plaque psoriasis, $P_{S A}$ psoriatic arthritis, $p S p A$ peripheral $S \mathrm{pA}, R A$ rheumatoid arthritis, $S p A$ spondyloarthritis, $U C$ ulcerative colitis, $U V$ uveitis 
was the most common serious infection event; no other event exceeded $0.2 / 100 \mathrm{PY}$. Risk of serious infection event was generally stable across time for all indications (Fig. 1).

The overall rate of serious TB was $0.2 / 100$ PY (Table 2). The highest rate of serious active TB was observed among patients with Ps, RA, PsA, and UV. No cases of active TB were seen in patients with HS or pSpA, and no cases of latent TB were seen among patients with Ps, HS, AS, nr-axSpA, PsA, or UC; however, testing for latent TB was not performed in most trials after treatment was started.

The overall rate of serious opportunistic infections, excluding TB and oral candidiasis, was less than $0.1 / 100$ PY (27 events), with the highest rate reported in UV studies (0.4/100 PY; 5 events); the rate of opportunistic infections did not exceed $0.1 / 100 \mathrm{PY}$ in other indications (Table 2). The most common serious opportunistic infection was esophageal candidiasis ( $<0.1 / 100$ PY; 4 events); no other event occurred more than twice. No serious opportunistic infections were reported in Ps, HS, AS, pSpA, and PsA studies (Table 2), and no events of serious oral candidiasis were reported in any of the studies. The rates of serious demyelinating disorders, lupus-like syndrome, and new onset/worsening of psoriasis and sarcoidosis across all indications were at most 0.1/100 PY. With the exception of UV (0.3/100 PY; 3 events), the rate of demyelinating disorders did not exceed $0.1 / 100 \mathrm{PY}$ across individual indications (25 events across all indications; Table 2). The overall rate of serious CHF was $0.2 / 100 \mathrm{PY}$ (97 events), with the highest rate (0.2/100 PY) occurring in patients with HS and RA (Table 2). No cases of progressive multifocal leukoencephalopathy were reported in these adalimumab clinical trials.

The overall rate of serious malignancies, excluding serious lymphoma, hepatosplenic T-cell lymphoma, leukemia, NMSC, and melanoma, was 0.6/100 PY across indications (ranging from 0.1 to $0.7 / 100 \mathrm{PY}$ ), with the highest rates reported among RA, UV, and UC studies (Table 2). The time to first malignancy, excluding lymphoma, hepatosplenic T-cell lymphoma, leukemia, NMSC, and melanoma, was similar between indications (Fig. 1). The SIR for all malignancies (excluding NMSC) was based on 321 observed events and was similar to the age-specific incidence rates (Fig. 2). The observed numbers of malignancies for most individual adalimumab populations (RA, Ps, AS, nr-axSpA, pSpA, and PsA) were below the agespecific rates. The SIR for lymphomas was based on 44 events (with 33 events in the RA population); the number of lymphomas observed across indications and in the RA studies were significantly greater than expected for agespecific incidence rates (Fig. 2). The SIR for NMSC was based on 280 events (with 191 basal cell carcinoma, 79 squamous cell carcinoma, and 10 unclassified), and the number of events across indications and in the RA, Ps, and CD studies was significantly greater than expected for age-specific incidence rates (Fig. 2). Although the SIR for NMSC was higher for HS and UV compared with Ps, RA, and CD, it was not significantly different from expected agespecific incidence rates in these two populations. The SIR for melanomas was based on 24 events (RA, 14 events; Ps, 6 events; UC, 3 events; AS, 1 event). In patients with Ps, the SIR for melanoma was significantly higher compared with age-specific incidence rate.

Overall, 232 deaths were recorded. Deaths were reported in each indication, with the highest rates among RA and UV studies (0.6/ $100 \mathrm{PY}$ ). For most of the adalimumab populations (Ps, RA, AS, PsA, UC, and CD), the observed number of deaths was below what would be expected in an age- and sex-adjusted general population (Fig. 3). For HS, nr-axSpA, pSpA, and UV studies, the small size of these trials precluded accurate assessment of the standardized mortality ratio, and the 95\% CIs all included 1.0.

\section{DISCUSSION}

This analysis of 29,967 adult patients, representing 10 indications and 56,916 PY of adalimumab exposure, is the most comprehensive safety analysis of adalimumab clinical trials reported to date. These results add to the previous safety analyses $[3,83]$ and the pediatric safety analysis [80] and demonstrate that no 


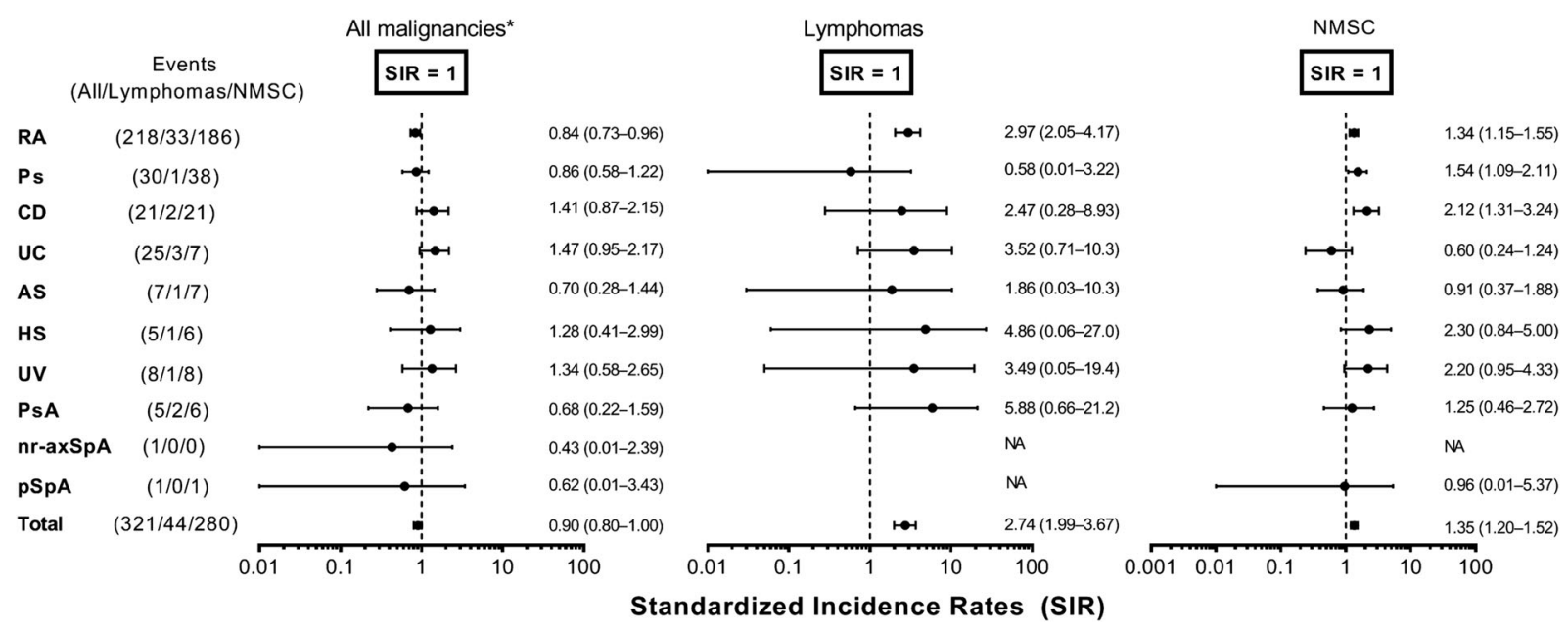

Fig. 2 Standardized incidence rates (95\% CI) of all malignancies (excluding NMSC), lymphomas, and NMSC for all indications and individual populations. SIR values less than 1 indicate fewer events were observed than expected. *All malignancies, excluding NMSC. Total population comprised 29,986 patients, including an additional 20 patients with Behçet's disease; data were missing for 1 patient with RA. $A S$ ankylosing spondylitis, $C D$ Crohn's disease, $H S$ hidradenitis suppurativa, NMSC nonmelanoma skin cancer, $n r-a x S p A$ non-radiographic axial $S p A, P s$ plaque psoriasis, $P_{S A}$ psoriatic arthritis, $p S p A$ peripheral $\mathrm{SpA}, R A$ rheumatoid arthritis, $S I R$ standardized incidence rate, $S p A$ spondyloarthritis, $U C$ ulcerative colitis, $U V$ uveitis

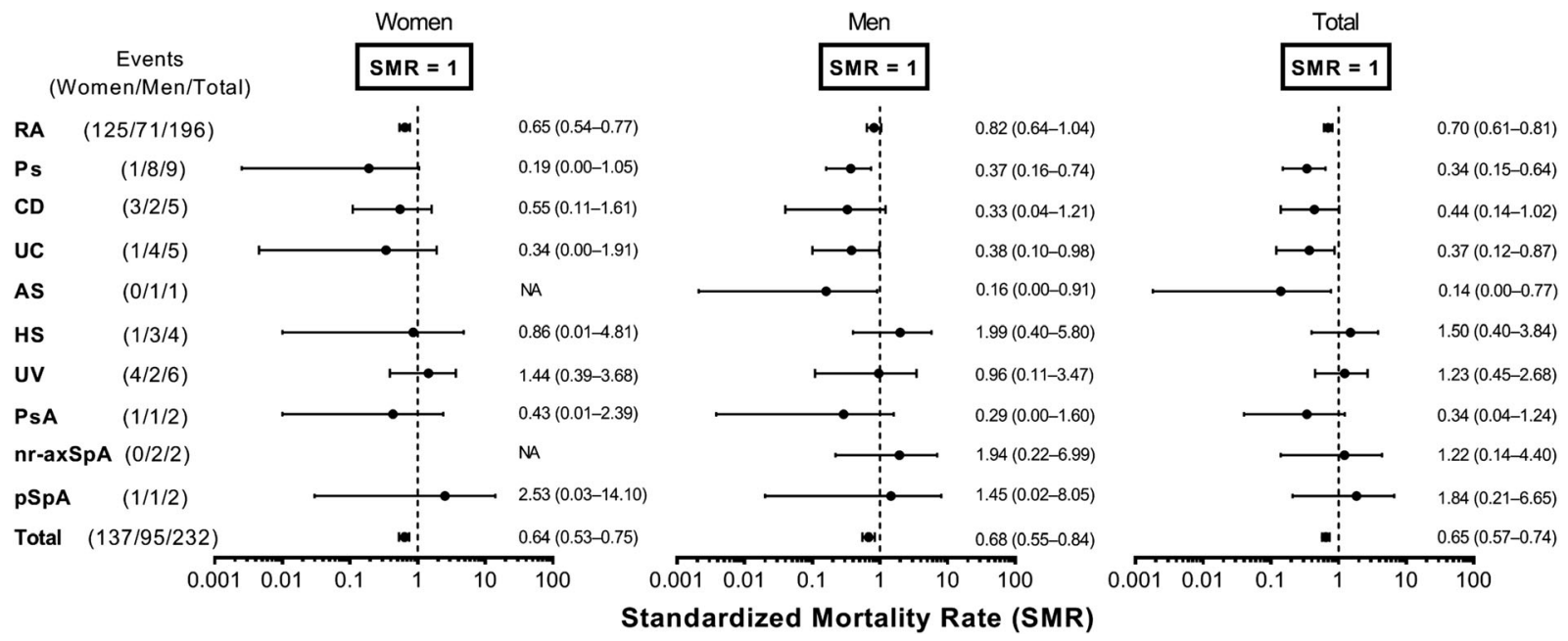

Fig. 3 Standardized mortality rates $(95 \%$ CI) for all indications and individual populations. Total population comprised 29,986 patients, including an additional 20 patients with Behçet's disease; data were missing for 1 patient with RA. $A S$ ankylosing spondylitis, $C D$ Crohn's

new safety findings were noted with increasing adalimumab exposure. Rates of SAEs of interest remained low and consistent with those reported for TNF inhibitors [4-7]. disease, $H S$ hidradenitis suppurativa, $n r$-axSpA non-radiographic axial $\mathrm{SpA}, P s$ plaque psoriasis, $P s A$ psoriatic arthritis, $p S p A$ peripheral $S \mathrm{pA}, R A$ rheumatoid arthritis, $S M R$ standardized mortality rate, $S p A$ spondyloarthritis, $U C$ ulcerative colitis, $U V$ uveitis

Infections remained the most commonly reported SAE across indications [3]. The overall rate of serious infections was 3.7/100 PY and ranged from 1.0 to $6.9 / 100 \mathrm{PY}$ across 
indications, with the highest rates reported among patients with CD, UV, RA, and UC and lowest among patients with pSpA, psoriasis, and AS. These are similar to serious infection rates reported for adalimumab in real-world registries [84-86] as well as for those reported for other TNF inhibitors [5-7, 84, 87, 88]. The higher rates of infections among patients with $\mathrm{CD}, \mathrm{RA}$, UV, and UC may be associated with concomitant corticosteroid use, which was highest among these patient populations, and patient characteristics, such as age and disease duration $[6,7,89,90]$. For example, for CD and UC, an increased rate of infection may occur early in the course of treatment, while in severe disease, infection may be related to the underlying disease, independent of treatment.

Opportunistic infections are possible with TNF inhibitor therapy as a result of their immunosuppressive nature [91]. Our long-term analysis demonstrated that the overall rates of serious opportunistic infections (excluding tuberculosis and oral candidiasis) and serious active tuberculosis were low. With the exception of UV, the rates of serious opportunistic infections were at most 0.1/100 PY across indications. The highest rate of serious active $\mathrm{TB}$ was found among patients with Ps, RA, PsA, and UV. The rates of serious opportunistic infections and active TBs were similar to the previous analysis [3] and were consistent with rates reported for adalimumab and other TNF inhibitors in clinical and real-world registry studies [86, 92-96].

The rates of other SAEs of interest were low. The overall rates of serious demyelinating disorders, lupus-like syndrome, and sarcoidosis were less than $0.1 / 100 \mathrm{PY}$. The overall rate of serious CHF was $0.2 / 100 \mathrm{PY}$, with the highest rates observed in HS and RA. This is noteworthy considering that patients with Ps have increased incidence and prevalence of cardiovascular risk factors [97]. However, the risk of cardiovascular events was also low with TNF inhibitor therapy in real-world registries of Ps $[4,86]$ and RA $[5,98]$. Furthermore, recent studies have suggested decreased risk of cardiovascular events with TNF inhibitor therapy in patients with Ps, RA, and PsA [99, 100]. Future studies are needed to confirm these results.
The SIR for all malignancies (excluding NMSC) was similar to the age-specific incidence rates and the observed numbers of malignancies for most individual adalimumab populations (RA, Ps, AS, PsA, nr-axSpA, and pSpA) were below the age-specific rates. Overall, the rate of serious malignancies was generally similar to that reported for TNF inhibitors in real-world Ps and RA registries [4, 101-103]. The time to onset of a first malignant event was stable across indications, suggesting no increased risk over time with prolonged treatment. However, the SIRs for lymphoma and NMSC in patients with RA were higher than those observed in agematched populations. In addition, increased incidences of NMSC were observed in patients with Ps and CD compared with age-matched populations. These findings were not entirely unexpected because increased risk of lymphoma and/or NMSC has been reported in patients with Ps, RA, and CD [104-108]. Furthermore, elevated rates of lymphoma and NMSC have been reported in patients with $\mathrm{CD}$ and $\mathrm{RA}$ receiving TNF inhibitors [103, 105, 109, 110]. However, TNF inhibitor treatment did not significantly increase the risk of lymphoma or NMSC in two other studies in patients with RA [108, 111]. Similar observations were reported in a Swedish registry analysis among patients with AS and PsA [112].

The risk of mortality was not increased in adalimumab-treated patients compared with the general population, and for most patients (including Ps) the observed number of deaths was below what would be expected in an ageand sex-adjusted population. There are a few possibilities to explain these interesting findings. First, the so-called healthy-cohort effect resulting from tighter monitoring and possible lifestyle changes (less smoking, healthier diet, more exercise) of patients in clinical trials may affect mortality. Second, the reduction in inflammation observed with anti-cytokine treatment may lead to fewer cardiovascular events and thus lowered mortality rate $[113,114]$, and decreased risk of cardiovascular events with TNF inhibitor therapy reported in patients with Ps, RA, and PsA $[99,100]$. However, it may also be possible that the improved life expectancy results from the rigorous 
screening (and exclusion criteria) before entering the trial and then the careful medical care that follows.

Limitations of this analysis of randomized clinical studies included the lack of real-life data and limited long-term data ( $>5$ years) for most patients. Nevertheless, this is a comprehensive long-term safety analysis of adalimumab studies that included 9355 patients with more than 2 years of exposure (compared with 5209 patients in the previous analysis) and 4003 patients with more than 5 years of exposure (compared with 1971 patients in the previous analysis) [3]. Other strengths of this analysis included rigorous safety monitoring in the clinical trials, reporting for several indications, and robust mortality data.

\section{CONCLUSIONS}

Taken together, this analysis of adalimumab trials with 56,916 PY of exposure demonstrated an overall safety profile consistent with previous findings $[3,83,115,116]$ and with other anti-TNF agents [4-7]. No new safety signals or tolerability issues were identified, and the risk of mortality was not increased compared with the general population.

\section{ACKNOWLEDGEMENTS}

AbbVie and the authors thank the patients who participated in the clinical trials and all study investigators for their contributions.

Funding. AbbVie sponsored the studies, contributed to their design, and participated in the collection, analysis, and interpretation of the data, and in the writing, reviewing, and final approval of the publication. The Rapid Service and Open Access Fees were funded by AbbVie.

Medical Writing, Editorial, and Other Assistance. Medical writing assistance was provided by Maria Hovenden, PhD, and Janet E. Matsuura, PhD, of Complete Publication Solutions, LLC, and was supported by AbbVie.
Authorship. All named authors meet the International Committee of Medical Journal Editors (ICMJE) criteria for authorship for this article, take responsibility for the integrity of the work as a whole, and have given their approval for this version to be published.

Disclosures. Dr. Burmester has received research grants, consulting fees, and/or speaker fees from AbbVie, Bristol-Myers Squibb, Merck, Pfizer, Roche, and UCB. Dr. Gordon has received research funding and/or consulting fees from AbbVie, Amgen, Boehringer Ingelheim, Celgene, Eli Lilly, Janssen, Novartis, Ortho, Pfizer, and Sun. Dr. Rosenbaum has received research grants, consulting fees, royalties and/or speaking fees from AbbVie, Alcon Research Institute, Eyevensys, Gilead, Janssen, Mallinckrodt, Novartis, Pfizer, Regeneron, Roche, Stem Cell Inc, UCB, and UptoDate. Dr. Arikan is a full-time employee of AbbVie and may own AbbVie stock and/or stock options. Ms. Lau is a full-time employee of AbbVie and may own AbbVie stock and/or stock options. Mr. Li is a full-time employee of AbbVie and may own AbbVie stock and/or stock options. Dr. Faccin is a full-time employee of AbbVie and may own AbbVie stock and/or stock options. Dr. Panaccione has received fees for serving as a consultant, paid speaker, and/or advisory board member, and/or received educational/research support from Abbott, AbbVie, ActoGeniX, AGI Therapeutics, Alba Therapeutics, Albireo, Alfa Wasserman, Amgen, AM-Pharma BV, Anaphore, Aptalis, Astellas, Athersys, Atlantic Healthcare, AstraZeneca, Baxter, BioBalance, Biogen Idec, Boehringer Ingelheim, Bristol-Myers Squibb, Celgene, Celek, Cellerix, Cerimon, ChemoCentryx, CoMentis, Cosmo Technologies, Coronado Biosciences, Cubist, Cytokine Pharmasciences, Eagle, Eisai, Elan, EnGene, Eli Lilly, Enteromedics, Exagen Diagnostics, Ferring, Flexion Therapeutics, Funxional Therapeutics, Genentech, Genzyme, Gilead, Given Imaging, GlaxoSmithKline, Hospira, Human Genome Sciences, Ironwood, Janssen, KaloBios, Lexicon, Lycera, Meda, Merck \& Co., Merck Research Laboratories, MerckSerono, Millennium, Nisshin Kyorin, Novartis, Novo Nordisk, NPS Pharmaceuticals, Optimer, Orexigen, PDL 
Biopharma, Pfizer, Procter and Gamble, Prometheus Laboratories, ProtAb, Purgenesis Technologies, Receptos, Relypsa, Salient, Salix, Santarus, Shire Pharmaceuticals, Sigmoid Pharma, Sirtris, S.L.A. Pharma, Takeda, Targacept, Teva, Therakos, Tillotts, TxCell SA, UCB, Vascular Biogenics, Viamet and Warner Chilcott.

Compliance with Ethics Guidelines. The individual studies were conducted in accordance with the International Conference on Harmonisation Good Clinical Practice guidelines and the Declaration of Helsinki, and were approved by institutional review boards and/or independent ethics committees according to local law. All patients provided informed consent before any study procedures were conducted.

Data Availability. AbbVie is committed to responsible data sharing regarding the clinical trials we sponsor. Access is provided to anonymized, patient- and trial-level data (analysis data sets), as well as other information (e.g., protocols and Clinical Study Reports) from AbbVie-sponsored phase II-IV global interventional clinical trials conducted in patients (completed as of May 2004, for products and indications approved in either the USA or the European Union), as long as the trials are not part of an ongoing or planned regulatory submission. This includes requests for clinical trial data for unlicensed products and indications. Access to this clinical trial data can be requested by any qualified researchers who engage in rigorous, independent scientific research, and will be provided following review and approval of a research proposal and Statistical Analysis Plan (SAP) and execution of a Data Sharing Agreement (DSA). Data requests can be submitted at any time and the data will be accessible for 12 months, with possible extensions considered. For more information on the process, or to submit a request, visit the following link: https://www.abbvie.com/our-science/clinicaltrials/clinical-trials-data-and-information-sharing/ data-and-information-sharing-with-qualifiedresearchers.html.
Open Access. This article is distributed under the terms of the Creative Commons Attribution-NonCommercial 4.0 International License (http://creativecommons.org/licenses/ by-nc/4.0/), which permits any noncommercial use, distribution, and reproduction in any medium, provided you give appropriate credit to the original author(s) and the source, provide a link to the Creative Commons license, and indicate if changes were made.

\section{REFERENCES}

1. Humira (adalimumab). Summary of product characteristics. Maidenhead: AbbVie; 2018.

2. Humira (adalimumab). Full prescribing information. North Chicago: AbbVie; 2018.

3. Burmester GR, Panaccione R, Gordon KB, McIlraith MJ, Lacerda AP. Adalimumab: long-term safety in 23458 patients from global clinical trials in rheumatoid arthritis, juvenile idiopathic arthritis, ankylosing spondylitis, psoriatic arthritis, psoriasis and Crohn's disease. Ann Rheum Dis. 2013;72: 517-24.

4. Reich K, Mrowietz U, Radtke MA, et al. Drug safety of systemic treatments for psoriasis: results from The German Psoriasis Registry PsoBest. Arch Dermatol Res. 2015;307:875-83.

5. Curtis JR, Jain A, Askling J, et al. A comparison of patient characteristics and outcomes in selected European and US rheumatoid arthritis registries. Semin Arthritis Rheum. 2010;40:2e1-14e1.

6. Cobo-Ibanez T, Descalzo MA, Loza-Santamaria E, Carmona L, Munoz-Fernandez S. Serious infections in patients with rheumatoid arthritis and other immune-mediated connective tissue diseases exposed to anti-TNF or rituximab: data from the Spanish registry BIOBADASER 2.0. Rheumatol Int. 2014;34:953-61.

7. Galloway JB, Hyrich KL, Mercer LK, et al. Anti-TNF therapy is associated with an increased risk of serious infections in patients with rheumatoid arthritis especially in the first 6 months of treatment: updated results from the British Society for Rheumatology Biologics Register with special emphasis on risks in the elderly. Rheumatology. 2011;50:124-31.

8. den Broeder A, van de Putte L, Rau R, et al. A single dose, placebo controlled study of the fully human 
anti-tumor necrosis factor-alpha antibody adalimumab (D2E7) in patients with rheumatoid arthritis. J Rheumatol. 2002;29:2288-98.

9. van de Putte LB, Rau R, Breedveld FC, et al. Efficacy and safety of the fully human anti-tumour necrosis factor alpha monoclonal antibody adalimumab (D2E7) in DMARD refractory patients with rheumatoid arthritis: a 12 week, phase II study. Ann Rheum Dis. 2003;62:1168-77.

10. Weinblatt ME, Keystone EC, Furst DE, et al. Adalimumab, a fully human anti-tumor necrosis factor $\alpha$ monoclonal antibody, for the treatment of rheumatoid arthritis in patients taking concomitant methotrexate: the ARMADA trial. Arthritis Rheum. 2003;48:35-45.

11. Rau R, Simianer S, van Riel PL, et al. Rapid alleviation of signs and symptoms of rheumatoid arthritis with intravenous or subcutaneous administration of adalimumab in combination with methotrexate. Scand J Rheumatol. 2004;33:145-53.

12. van de Putte LB, Atkins C, Malaise M, et al. Efficacy and safety of adalimumab as monotherapy in patients with rheumatoid arthritis for whom previous disease modifying antirheumatic drug treatment has failed. Ann Rheum Dis. 2004;63:508-16.

13. Breedveld FC, Weisman MH, Kavanaugh AF, et al. The PREMIER study: a multicenter, randomized, double-blind clinical trial of combination therapy with adalimumab plus methotrexate versus methotrexate alone or adalimumab alone in patients with early, aggressive rheumatoid arthritis who had not had previous methotrexate treatment. Arthritis Rheum. 2006;54:26-37.

14. Keystone EC, Kavanaugh AF, Sharp JT, et al. Radiographic, clinical, and functional outcomes of treatment with adalimumab (a human anti-tumor necrosis factor monoclonal antibody) in patients with active rheumatoid arthritis receiving concomitant methotrexate therapy: a randomized, placebo-controlled, 52-week trial. Arthritis Rheum. 2004;50:1400-11.

15. Furst DE, Kavanaugh A, Florentinus S, Kupper H, Karunaratne M, Birbara CA. Final 10-year effectiveness and safety results from study DE020: adalimumab treatment in patients with rheumatoid arthritis and an inadequate response to standard therapy. Rheumatology (Oxford). 2015;54:2188-97.

16. Furst DE, Schiff MH, Fleischmann RM, et al. Adalimumab, a fully human anti tumor necrosis factoralpha monoclonal antibody, and concomitant standard antirheumatic therapy for the treatment of rheumatoid arthritis: results of STAR (Safety Trial of Adalimumab in Rheumatoid Arthritis). J Rheumatol. 2003;30:2563-71.
17. Burmester GR, Mariette X, Montecucco C, et al. Adalimumab alone and in combination with disease-modifying antirheumatic drugs for the treatment of rheumatoid arthritis in clinical practice: the Research in Active Rheumatoid Arthritis (ReAct) trial. Ann Rheum Dis. 2007;66:732-9.

18. Bejarano V, Quinn M, Conaghan PG, et al. Effect of the early use of the anti-tumor necrosis factor adalimumab on the prevention of job loss in patients with early rheumatoid arthritis. Arthritis Rheum. 2008;59:1467-74.

19. van der Bijl AE, Breedveld FC, Antoni CE, et al. An open-label pilot study of the effectiveness of adalimumab in patients with rheumatoid arthritis and previous infliximab treatment: relationship to reasons for failure and anti-infliximab antibody status. Clin Rheumatol. 2008;27:1021-8.

20. Chen DY, Chou SJ, Hsieh TY, et al. Randomized, double-blind, placebo-controlled, comparative study of human anti-TNF antibody adalimumab in combination with methotrexate and methotrexate alone in Taiwanese patients with active rheumatoid arthritis. J Formos Med Assoc. 2009;108:310-9.

21. Haraoui B, Cividino A, Stewart J, Guerette B, Keystone EC. Safety and effectiveness of adalimumab in a clinical setting that reflects Canadian standard of care for the treatment of rheumatoid arthritis (RA): results from the CanACT study. BMC Musculoskelet Disord. 2011;12:261.

22. Miyasaka N, Change Study Investigators. Clinical investigation in highly disease-affected rheumatoid arthritis patients in Japan with adalimumab applying standard and general evaluation: the CHANGE study. Mod Rheumatol. 2008;18:252-62.

23. Burmester GR, Matucci-Cerinic M, Mariette X, et al. Safety and effectiveness of adalimumab in patients with rheumatoid arthritis over 5 years of therapy in a phase $3 \mathrm{~b}$ and subsequent postmarketing observational study. Arthritis Res Ther. 2014;16:R24.

24. Huang F, Zhang FC, Bao CD, et al. Adalimumab plus methotrexate for the treatment of rheumatoid arthritis: a multi-center randomized, double-blind, placebo-controlled clinical study. Zhonghua Nei Ke Za Zhi. 2009;48:916-21.

25. Kavanaugh A, Fleischmann RM, Emery P, et al. Clinical, functional and radiographic consequences of achieving stable low disease activity and remission with adalimumab plus methotrexate or methotrexate alone in early rheumatoid arthritis: 26-week results from the randomised, controlled OPTIMA study. Ann Rheum Dis. 2013;72:64-71.

26. Takeuchi T, Yamanaka H, Ishiguro N, et al. Adalimumab, a human anti-TNF monoclonal antibody, 
outcome study for the prevention of joint damage in Japanese patients with early rheumatoid arthritis: the HOPEFUL 1 study. Ann Rheum Dis. 2014;73: $536-43$.

27. Kaeley GS, Evangelisto AM, Nishio MJ, et al. Methotrexate dosage reduction upon adalimumab initiation: clinical and ultrasonographic outcomes from the randomized noninferiority MUSICA trial. J Rheumatol. 2016;43:1480-9.

28. Burmester GR, Kivitz AJ, Kupper H, et al. Efficacy and safety of ascending methotrexate dose in combination with adalimumab: the randomised CONCERTO trial. Ann Rheum Dis. 2015;74: $1037-44$

29. Kivitz A, Cohen S, Dowd JE, et al. Clinical assessment of pain, tolerability, and preference of an autoinjection pen versus a prefilled syringe for patient self-administration of the fully human, monoclonal antibody adalimumab: the TOUCH trial. Clin Ther. 2006;28:1619-29.

30. Nash P, Vanhoof J, Hall S, et al. Randomized crossover comparison of injection site pain with $40 \mathrm{mg} / 0.4$ or $0.8 \mathrm{~mL}$ formulations of adalimumab in patients with rheumatoid arthritis. Rheumatol Ther. 2016;3:257-70.

31. Gordon KB, Langley RG, Leonardi C, et al. Clinical response to adalimumab treatment in patients with moderate to severe psoriasis: double-blind, randomized controlled trial and open-label extension study. J Am Acad Dermatol. 2006;55:598-606.

32. Gordon K, Blum R, Papp K, et al. Efficacy and safety of adalimumab treatment in patients with moderate to severe psoriasis: a double-blind, randomized clinical trial. Psoriasis Forum. 2007;13:4-11.

33. Larian A, Emer JJ, Gordon K, et al. Efficacy and safety of a second adalimumab treatment cycle in psoriasis patients who relapsed after adalimumab discontinuation or dosage reduction: a doubleblind, randomized, placebo-controlled trial. Psoriasis Forum. 2011;17:88-96.

34. Menter A, Tyring SK, Gordon K, et al. Adalimumab therapy for moderate to severe psoriasis: a randomized, controlled phase III trial. J Am Acad Dermatol. 2008;58:106-15.

35. Gordon K, Papp K, Poulin Y, Gu Y, Rozzo S, Sasso EH. Long-term efficacy and safety of adalimumab in patients with moderate to severe psoriasis treated continuously over 3 years: results from an openlabel extension study for patients from REVEAL. J Am Acad Dermatol. 2012;66:241-51.

36. Asahina A, Nakagawa H, Etoh T, Ohtsuki M, Adalimumab M04-688 Study Group. Adalimumab in
Japanese patients with moderate to severe chronic plaque psoriasis: efficacy and safety results from a phase II/III randomized controlled study. J Dermatol. 2010;37:299-310.

37. Asahina A, Ohtsuki M, Etoh T, et al. Adalimumab treatment optimization for psoriasis: results of a long-term phase 2/3 Japanese study. J Dermatol. 2015;42:1042-52.

38. Saurat JH, Stingl G, Dubertret L, et al. Efficacy and safety results from the randomized controlled comparative study of adalimumab vs. methotrexate vs. placebo in patients with psoriasis (CHAMPION). Br J Dermatol. 2008;158:558-66.

39. Thaçi D, Ortonne JP, Chimenti S, et al. A phase IIIb, multicentre, randomized, double-blind, vehiclecontrolled study of the efficacy and safety of adalimumab with and without calcipotriol/betamethasone topical treatment in patients with moderate to severe psoriasis: the BELIEVE study. Br J Dermatol. 2010;163:402-11.

40. Strober BE, Poulin Y, Kerdel FA, et al. Switching to adalimumab for psoriasis patients with a suboptimal response to etanercept, methotrexate, or phototherapy: efficacy and safety results from an openlabel study. J Am Acad Dermatol. 2011;64:671-81.

41. Leonardi C, Langley RG, Papp K, et al. Adalimumab for treatment of moderate to severe chronic plaque psoriasis of the hands and feet: efficacy and safety results from REACH, a randomized, placebo-controlled, double-blind trial. Arch Dermatol. 2011;147:429-36.

42. Cai L, Gu J, Zheng J, et al. Efficacy and safety of adalimumab in Chinese patients with moderate-tosevere plaque psoriasis: results from a phase 3 , randomized, placebo-controlled, double-blind study. J Eur Acad Dermatol Venereol. 2017;31:89-95.

43. Elewski BE, Okun MM, Papp K, et al. Adalimumab for nail psoriasis: efficacy and safety from the first 26 weeks of a phase 3, randomized, placebo-controlled trial. J Am Acad Dermatol. 2018;78(90-9):e1.

44. Papp K, Ho V, Teixeira HD, Guerette B, Chen K, Lynde C. Efficacy and safety of adalimumab when added to inadequate therapy for the treatment of psoriasis: results of PRIDE, an open-label, multicentre, phase IIIb study. J Eur Acad Dermatol Venereol. 2012;26:1007-13.

45. Hanauer SB, Sandborn WJ, Rutgeerts P, et al. Human anti-tumor necrosis factor monoclonal antibody (adalimumab) in Crohn's disease: the CLASSIC-I trial. Gastroenterology. 2006;130:323-33.

46. Colombel JF, Sandborn WJ, Rutgeerts P, et al. Adalimumab for maintenance of clinical response 
and remission in patients with Crohn's disease: the CHARM trial. Gastroenterology. 2007;132:52-65.

47. Sandborn WJ, Hanauer SB, Rutgeerts $P$, et al. Adalimumab for maintenance treatment of Crohn's disease: results of the CLASSIC II trial. Gut. 2007;56: 1232-9.

48. Panaccione R, Colombel JF, Sandborn WJ, et al. Adalimumab sustains clinical remission and overall clinical benefit after 2 years of therapy for Crohn's disease. Aliment Pharmacol Ther. 2010;31:1296-309.

49. Sandborn WJ, Rutgeerts P, Enns R, et al. Adalimumab induction therapy for Crohn disease previously treated with infliximab: a randomized trial. Ann Intern Med. 2007;146:829-38.

50. Watanabe M, Hibi T, Lomax KG, et al. Adalimumab for the induction and maintenance of clinical remission in Japanese patients with Crohn's disease. J Crohns Colitis. 2012;6:160-73.

51. Watanabe M, Hibi T, Mostafa NM, et al. Long-term safety and efficacy of adalimumab in Japanese patients with moderate to severe Crohn's disease. J Crohns Colitis. 2014;8:1407-16.

52. Rutgeerts P, Van Assche G, Sandborn WJ, et al. Adalimumab induces and maintains mucosal healing in patients with Crohn's disease: data from the EXTEND trial. Gastroenterology. 2012;142:1102-11.

53. Lichtiger S, Binion DG, Wolf DC, et al. The CHOICE trial: adalimumab demonstrates safety, fistula healing, improved quality of life and increased work productivity in patients with Crohn's disease who failed prior infliximab therapy. Aliment Pharmacol Ther. 2010;32:1228-39.

54. Löfberg R, Louis EV, Reinisch W, et al. Adalimumab produces clinical remission and reduces extraintestinal manifestations in Crohn's disease: results from CARE. Inflamm Bowel Dis. 2012;18:1-9.

55. Panaccione R, Loftus EV Jr, Binion D, et al. Efficacy and safety of adalimumab in Canadian patients with moderate to severe Crohn's disease: results of the Adalimumab in Canadian SubjeCts with ModErate to Severe Crohn's DiseaSe (ACCESS) trial. Can J Gastroenterol. 2011;25:419-25.

56. Colombel JF, Panaccione R, Bossuyt P, et al. Effect of tight control management on Crohn's disease (CALM): a multicentre, randomised, controlled phase 3 trial. Lancet. 2017;390:2779-89.

57. Wu KC, Ran ZH, Gao X, et al. Adalimumab induction and maintenance therapy achieve clinical remission and response in Chinese patients with Crohn's disease. Intest Res. 2016;14:152-63.
58. Lambert RG, Salonen D, Rahman P, et al. Adalimumab significantly reduces both spinal and sacroiliac joint inflammation in patients with ankylosing spondylitis: a multicenter, randomized, double-blind, placebo-controlled study. Arthritis Rheum. 2007;56:4005-14.

59. Dougados M, Luo MP, Maksymowych WP, et al. Evaluation of the patient acceptable symptom state as an outcome measure in patients with ankylosing spondylitis: data from a randomized controlled trial. Arthritis Rheum. 2008;59:553-60.

60. Rudwaleit M, Rodevand E, Holck P, et al. Adalimumab effectively reduces the rate of anterior uveitis flares in patients with active ankylosing spondylitis: results of a prospective open-label study. Ann Rheum Dis. 2009;68:696-701.

61. Kobayashi S, Harigai M, Mozaffarian N, et al. A multicenter, open-label, efficacy, pharmacokinetic, and safety study of adalimumab in Japanese patients with ankylosing spondylitis. Mod Rheumatol. 2012;22:589-97.

62. Huang F, Gu J, Zhu P, et al. Efficacy and safety of adalimumab in Chinese adults with active ankylosing spondylitis: results of a randomised, controlled trial. Ann Rheum Dis. 2014;73:587-94.

63. Reinisch W, Sandborn WJ, Hommes DW, et al. Adalimumab for induction of clinical remission in moderately to severely active ulcerative colitis: results of a randomised controlled trial. Gut. 2011;60:780-7.

64. Sandborn WJ, van Assche G, Reinisch W, et al. Adalimumab induces and maintains clinical remission in patients with moderate-to-severe ulcerative colitis. Gastroenterology. 2012;142(257-65):e1-3.

65. Colombel JF, Sandborn WJ, Ghosh S, et al. Four-year maintenance treatment with adalimumab in patients with moderately to severely active ulcerative colitis: data from ULTRA 1, 2, and 3. Am J Gastroenterol. 2014;109:1771-80.

66. Suzuki Y, Motoya S, Hanai H, et al. Efficacy and safety of adalimumab in Japanese patients with moderately to severely active ulcerative colitis. J Gastroenterol. 2014;49:283-94.

67. Travis S, Feagan BG, Peyrin-Biroulet L, et al. Effect of adalimumab on clinical outcomes and health-related quality of life among patients with ulcerative colitis in a clinical practice setting: results from InspirADA. J Crohns Colitis. 2017;11:1317-25.

68. Kimball AB, Kerdel F, Adams D, et al. Adalimumab for the treatment of moderate to severe hidradenitis suppurativa: a parallel randomized trial. Ann Intern Med. 2012;157:846-55. 
69. Kimball AB, Okun MM, Williams DA, et al. Two phase 3 trials of adalimumab for hidradenitis suppurativa. N Engl J Med. 2016;375:422-34.

70. Mease PJ, Gladman DD, Ritchlin CT, et al. Adalimumab for the treatment of patients with moderately to severely active psoriatic arthritis: results of a double-blind, randomized, placebo-controlled trial. Arthritis Rheum. 2005;52:3279-89.

71. Mease PJ, Ory P, Sharp JT, et al. Adalimumab for long-term treatment of psoriatic arthritis: 2-year data from the adalimumab effectiveness in psoriatic arthritis trial (ADEPT). Ann Rheum Dis. 2009;68: 702-9.

72. Genovese MC, Mease PJ, Thomson GT, et al. Safety and efficacy of adalimumab in treatment of patients with psoriatic arthritis who had failed disease modifying antirheumatic drug therapy. J Rheumatol. $2007 ; 34: 1040-50$.

73. Rudwaleit M, Van den Bosch F, Kron M, Kary S, Kupper H. Effectiveness and safety of adalimumab in patients with ankylosing spondylitis or psoriatic arthritis and history of anti-tumor necrosis factor therapy. Arthritis Res Ther. 2010;12:R117.

74. Jaffe GJ, Dick AD, Brezin AP, et al. Adalimumab in patients with active noninfectious uveitis. N Engl J Med. 2016;375:932-43.

75. Nguyen QD, Merrill PT, Jaffe GJ, et al. Adalimumab for prevention of uveitic flare in patients with inactive non-infectious uveitis controlled by corticosteroids (VISUAL II): a multicentre, doublemasked, randomised, placebo-controlled phase 3 trial. Lancet. 2016;388:1183-92.

76. Suhler EB, Adan A, Brezin AP, et al. Safety and efficacy of adalimumab in patients with noninfectious uveitis in an ongoing open-label study: VISUAL III. Ophthalmology. 2018;125:1075-87.

77. Sieper J, van der Heijde D, Dougados M, et al. Efficacy and safety of adalimumab in patients with non-radiographic axial spondyloarthritis: results of a randomised placebo-controlled trial (ABILITY-1). Ann Rheum Dis. 2013;72:815-22.

78. Landewe R, Sieper J, Mease P, et al. Efficacy and safety of continuing versus withdrawing adalimumab therapy in maintaining remission in patients with non-radiographic axial spondyloarthritis (ABILITY-3): a multicentre, randomised, double-blind study. Lancet. 2018;392:134-44.

79. Mease P, Sieper J, Van den Bosch F, Rahman P, Karunaratne PM, Pangan AL. Randomized controlled trial of adalimumab in patients with nonpsoriatic peripheral spondyloarthritis. Arthritis Rheum. 2015;67:914-23.
80. Horneff G, Seyger MMB, Arikan D, et al. Safety of adalimumab in pediatric patients with polyarticular juvenile idiopathic arthritis, enthesitis-related arthritis, psoriasis, and Crohn's disease. J Pediatr. 2018;201:166-75.

81. Scotto J, Fears TR, Fraumeni JF, National Cancer Institute (U.S.). Incidence of nonmelanoma skin cancer in the United States. Bethesda: U.S. Dept. of Health and Human Services, Public Health Service, National Institutes of Health, National Cancer Institute; 1983.

82. Breslow NE, Day NE. Statistical methods in cancer research: volume II-the design and analysis of cohort studies. Lyon: International Agency for Research on Cancer; 1987.

83. Burmester GR, Mease P, Dijkmans BAC, et al. Adalimumab safety and mortality rates from global clinical trials of six immune-mediated inflammatory diseases. Ann Rheum Dis. 2009;68:1863-9.

84. Atzeni F, Sarzi-Puttini P, Botsios C, et al. Long-term anti-TNF therapy and the risk of serious infections in a cohort of patients with rheumatoid arthritis: comparison of adalimumab, etanercept and infliximab in the GISEA registry. Autoimmun Rev. 2012;12:225-9.

85. Davila-Seijo P, Dauden E, Descalzo MA, et al. Infections in moderate to severe psoriasis patients treated with biological drugs compared to classic systemic drugs: findings from the BIOBADADERM registry. J Invest Dermatol. 2016;137:313-21.

86. Menter A, Thaci D, Wu JJ, et al. Long-term safety and effectiveness of adalimumab for moderate to severe psoriasis: results from 7-year interim analysis of the ESPRIT registry. Dermatol Ther (Heidelb). 2017;7:365-81.

87. van Dartel SA, Fransen J, Kievit W, et al. Difference in the risk of serious infections in patients with rheumatoid arthritis treated with adalimumab, infliximab and etanercept: results from the Dutch rheumatoid arthritis monitoring (DREAM) registry. Ann Rheum Dis. 2013;72:895-900.

88. Strangfeld A, Eveslage M, Schneider M, et al. Treatment benefit or survival of the fittest: what drives the time-dependent decrease in serious infection rates under TNF inhibition and what does this imply for the individual patient? Ann Rheum Dis. 2011;70:1914-20.

89. Doran MF, Crowson CS, Pond GR, O'Fallon WM, Gabriel SE. Predictors of infection in rheumatoid arthritis. Arthritis Rheum. 2002;46:2294-300.

90. Lichtenstein GR, Feagan BG, Cohen RD, et al. Serious infections and mortality in association with 
therapies for Crohn's disease: TREAT registry. Clin Gastroenterol Hepatol. 2006;4:621-30.

91. Ali T, Kaitha S, Mahmood S, Ftesi A, Stone J, Bronze MS. Clinical use of anti-TNF therapy and increased risk of infections. Drug Healthc Patient Saf. 2013;5: 79-99.

92. Tubach F, Salmon D, Ravaud P, et al. Risk of tuberculosis is higher with anti-tumor necrosis factor monoclonal antibody therapy than with soluble tumor necrosis factor receptor therapy: the threeyear prospective French Research Axed on Tolerance of Biotherapies registry. Arthritis Rheum. 2009;60:1884-94.

93. Yonekura CL, Oliveira RDR, Titton DC, et al. Incidence of tuberculosis among patients with rheumatoid arthritis using TNF blockers in Brazil: data from the Brazilian Registry of Biological Therapies in Rheumatic Diseases (Registro Brasileiro de Monitoracao de Terapias Biologicas-BiobadaBrasil). Rev Bras Reumatol Engl Ed. 2017;57:477-83.

94. Cantini F, Niccoli L, Goletti D. Adalimumab, etanercept, infliximab, and the risk of tuberculosis: data from clinical trials, national registries, and postmarketing surveillance. J Rheumatol Suppl. 2014;91:47-55.

95. Salmon-Ceron D, Tubach F, Lortholary O, et al. Drug-specific risk of non-tuberculosis opportunistic infections in patients receiving anti-TNF therapy reported to the 3-year prospective French RATIO registry. Ann Rheum Dis. 2011;70:616-23.

96. Dixon WG, Hyrich KL, Watson KD, et al. Drugspecific risk of tuberculosis in patients with rheumatoid arthritis treated with anti-TNF therapy: results from the British Society for Rheumatology Biologics Register (BSRBR). Ann Rheum Dis. 2010;69:522-8.

97. Egeberg A, Skov L. Management of cardiovascular disease in patients with psoriasis. Expert Opin Pharmacother. 2016;17:1509-16.

98. Ljung L, Simard JF, Jacobsson L, Rantapaa-Dahlqvist S, Askling J, Anti-Rheumatic Therapy in Sweden Study Group. Treatment with tumor necrosis factor inhibitors and the risk of acute coronary syndromes in early rheumatoid arthritis. Arthritis Rheum. 2012;64:42-52.

99. Roubille C, Richer V, Starnino T, et al. The effects of tumour necrosis factor inhibitors, methotrexate, non-steroidal anti-inflammatory drugs and corticosteroids on cardiovascular events in rheumatoid arthritis, psoriasis and psoriatic arthritis: a systematic review and meta-analysis. Ann Rheum Dis. 2015;74:480-9.
100. Wu JJ, Guerin A, Sundaram M, Dea K, Cloutier M, Mulani P. Cardiovascular event risk assessment in psoriasis patients treated with tumor necrosis factor-alpha inhibitors versus methotrexate. J Am Acad Dermatol. 2017;76:81-90.

101. Strangfeld A, Hierse F, Rau R, et al. Risk of incident or recurrent malignancies among patients with rheumatoid arthritis exposed to biologic therapy in the German biologics register RABBIT. Arthritis Res Ther. 2010;12:R5.

102. Askling J, van Vollenhoven RF, Granath F, et al. Cancer risk in patients with rheumatoid arthritis treated with anti-tumor necrosis factor alpha therapies: does the risk change with the time since start of treatment? Arthritis Rheum. 2009;60:3180-9.

103. Askling J, Baecklund E, Granath F, et al. Anti-tumour necrosis factor therapy in rheumatoid arthritis and risk of malignant lymphomas: relative risks and time trends in the Swedish Biologics Register. Ann Rheum Dis. 2009;68:648-53.

104. Hellgren K, Smedby KE, Feltelius N, Baecklund E, Askling J. Do rheumatoid arthritis and lymphoma share risk factors?: a comparison of lymphoma and cancer risks before and after diagnosis of rheumatoid arthritis. Arthritis Rheum. 2010;62:1252-8.

105. Long MD, Herfarth $\mathrm{HH}$, Pipkin CA, Porter CQ, Sandler RS, Kappelman MD. Increased risk for nonmelanoma skin cancer in patients with inflammatory bowel disease. Clin Gastroenterol Hepatol. 2010;8:268-74.

106. Stern RS, Liebman EJ, Vakeva L. Oral psoralen and ultraviolet-A light (PUVA) treatment of psoriasis and persistent risk of nonmelanoma skin cancer. PUVA Follow-up Study. J Natl Cancer Inst. 1998;90: 1278-84.

107. Baecklund E, Iliadou A, Askling J, et al. Association of chronic inflammation, not its treatment, with increased lymphoma risk in rheumatoid arthritis. Arthritis Rheum. 2006;54:692-701.

108. Chakravarty EF, Michaud K, Wolfe F. Skin cancer, rheumatoid arthritis, and tumor necrosis factor inhibitors. J Rheumatol. 2005;32:2130-5.

109. Siegel CA, Marden SM, Persing SM, Larson RJ, Sands BE. Risk of lymphoma associated with combination anti-tumor necrosis factor and immunomodulator therapy for the treatment of Crohn's disease: a metaanalysis. Clin Gastroenterol Hepatol. 2009;7:874-81.

110. Wolfe F, Michaud K. Biologic treatment of rheumatoid arthritis and the risk of malignancy: analyses from a large US observational study. Arthritis Rheum. 2007;56:2886-95. 
111. Mercer LK, Regierer AC, Mariette X, et al. Spectrum of lymphomas across different drug treatment groups in rheumatoid arthritis: a European registries collaborative project. Ann Rheum Dis. 2017;76:2025-30.

112. Hellgren K, Smedby KE, Backlin C, et al. Ankylosing spondylitis, psoriatic arthritis, and risk of malignant lymphoma: a cohort study based on nationwide prospectively recorded data from Sweden. Arthritis Rheumatol. 2014;66:1282-90.

113. Sattar N, McCarey DW, Capell H, McInnes IB. Explaining how "high-grade" systemic inflammation accelerates vascular risk in rheumatoid arthritis. Circulation. 2003;108:2957-63.

114. Ridker PM, Everett BM, Thuren T, et al. Antiinflammatory therapy with canakinumab for atherosclerotic disease. N Engl J Med. 2017;377: 1119-31.

115. Burmester GR, Landewe R, Genovese MC, et al. Adalimumab long-term safety: infections, vaccination response and pregnancy outcomes in patients with rheumatoid arthritis. Ann Rheum Dis. 2017;76:414-7.

116. Leonardi C, Papp K, Strober B, et al. The long-term safety of adalimumab treatment in moderate to severe psoriasis: a comprehensive analysis of all adalimumab exposure in all clinical trials. Am J Clin Dermatol. 2011;12:321-37. 